\title{
Residual stresses in thermite welded rails: significance of additional forging
}

\author{
B. Lennart Josefson ${ }^{1}$ (D) $\cdot$ R. Bisschop ${ }^{1} \cdot$ M. Messaadi ${ }^{2} \cdot$ J. Hantusch $^{3}$
}

Received: 6 December 2019 / Accepted: 27 April 2020 / Published online: 17 May 2020

(C) The Author(s) 2020

\begin{abstract}
The aluminothermic welding (ATW) process is the most commonly used welding process for welding rails (track) in the field. The large amount of weld metal added in the ATW process may result in a wide uneven surface zone on the rail head, which may, in rare cases, lead to irregularities in wear and plastic deformation due to high dynamic wheel-rail forces as wheels pass. The present paper studies the introduction of additional forging to the ATW process, intended to reduce the width of the zone affected by the heat input, while not creating a more detrimental residual stress field. Simulations using a novel thermo-mechanical FE model of the ATW process show that addition of a forging pressure leads to a somewhat smaller width of the zone affected by heat. This is also found in a metallurgical examination, showing that this zone (weld metal and heat-affected zone) is fully pearlitic. Only marginal differences are found in the residual stress field when additional forging is applied. In both cases, large tensile residual stresses are found in the rail web at the weld. Additional forging may increase the risk of hot cracking due to an increase in plastic strains within the welded area.
\end{abstract}

Keywords Aluminothermic welding $\cdot$ FEM $\cdot$ Residual stress $\cdot$ Hardness $\cdot$ Pearlite

\section{Introduction}

Continuous welded rails have been in use since the 1930s. The most common continuous welding method for welded rails, or welded segments of rails, in the track is aluminothermic welding (ATW), see for example Meric et al. [1] and Chen et al. [2]. This method is also considered for replacing defective or broken rails (or welds) and installing rail insulation joints. In ATW, the rails are properly cut, cleaned, and aligned. The two rail sections are then positioned collinearly with a gap in between before a ceramic mold is placed around them. The two rail ends are then preheated with an oxy-propane torch.

Recommended for publication by Commission X - Structural Performances of Welded Joints - Fracture Avoidance

B. Lennart Josefson

lejo@chalmers.se

1 Department of Industrial and Materials Science, Chalmers University of Technology, Göteborg, Sweden

2 Faculty of Civil Engineering and Geosciences, Railway Engineering Group, Delft University of Technology, Delft, The Netherlands

3 Goldschmidt GmbH, Leipzig, Germany
This ensures that the assembly is dry. In the next step, a reaction crucible is mounted on the top of the mold. The crucible is filled with thermite, consisting of iron alloy, iron oxide, and aluminum granules. Upon ignition, a highly exothermic reaction melts the mixture, causing it to flow out of the crucible and into the weld gap. The molten iron provides the heat for fusion along with weld metal. After the weld pool has cooled for some time, a hydraulic shearing device removes excess material. Figure 1 shows schematically the different steps in the ATW process.

Other methods for in-track welding are flash-butt welding (FBW) and gas pressure welding (GP). These methods are more often used with stationary equipment and used to weld larger sections of rails which are then transported out to the track, and also, enclosed-arc (EA) welding, i.e., manual metal arc welding may be used for welding in track, though it is mainly used for replacement welding. The weld quality achieved, for example, for fatigue performance, may be best for FBW, GP, and ATW, followed by EA. ATW is often used in-track, because of several factors such as easy alignment and simplicity.

In the track, rail welds constitute areas where the mechanical and metallurgical properties differ from the rolled rail material, and may, in rare cases act as starting points for rail 
Fig. 1 Overview of a typical aluminothermic welding (ATW) process

\begin{tabular}{|c|c|c|c|c|c|}
\hline PREHEATING & TAPPING & POURING & SOLIDIFICATION & SHEARING & COOLING \\
\hline $\begin{array}{l}\text { The rail and sand } \\
\text { mould are } \\
\text { preheated to ensure } \\
\text { they are dry and to } \\
\text { slow down cooling } \\
\text { rates in the weld } \\
\text { area }\end{array}$ & $\begin{array}{l}\text { The reaction } \\
\text { crucible is mounted } \\
\text { on top of the mould. } \\
\text { The mixture of iron } \\
\text { alloy, ironoxide and } \\
\text { Thermite is ignited. }\end{array}$ & $\begin{array}{l}\text { The liquid steel } \\
\text { flows out of the } \\
\text { crucible. down the } \\
\text { weld gap and fills } \\
\text { the mould. }\end{array}$ & $\begin{array}{l}\text { The liquid steel cools is } \\
\text { allowed to cool down } \\
\text { and solidify. }\end{array}$ & $\begin{array}{l}\text { Sections of the } \\
\text { mould and weld } \\
\text { metal are removed } \\
\text { by a hydraulic } \\
\text { shearing device. }\end{array}$ & $\begin{array}{l}\text { The weld metal is } \\
\text { left to cool down. }\end{array}$ \\
\hline
\end{tabular}

fracture or fatigue cracks. These may be observed as a combination of defects resulting from welding in areas with tensile welding residual stresses. Such problems have been addressed frequently in the literature for ATW and FBW [3-6].

The ATW process creates residual stresses that may be highly tensile in certain regions due to high temperature gradients and local plastic yielding. While this has been shown in experimental results for the welding residual field [7-9], it has not yet been shown numerically. A similar residual stress field to that of the FBW method, which is seen in numerical and experimental results [10-13], is expected. In general, both methods will create qualitatively the same residual stress field with tensile vertical and longitudinal stresses in the web lower head region. The longitudinal stress may be compressive in the rail head and in the rail foot. The tensile vertical stresses in the web region as well as in the transition to the rail head may contribute to growth of horizontal cracks from defects. This is a significant and known problem with rail welds. Moreover, the residual stresses in the web region are not redistributed by typical operational loads (passing of railway wheels), i.e., contact pressure on the rail head and bending loads in the rail foot. The effect of welding residual stresses on the fatigue behavior of rail welds and means to improve the fatigue of rail welds, mainly for FBW, have been studied in [14-17].

The present paper also addresses the problem of uneven wear in rail welds. Rail welds have a wide heat-affected zone, HAZ, (45 mm for FBW and even more for ATW and GP) creating a large zone with hardness variations and thus an irregular resistance to wear along the rail head. This, in turn, leads to cupping and batter at the weld giving (additional) dynamic wheel-rail contact forces on the track and possibly a reduction in its fatigue life, see Grossoni et al. [18] for a quantification of these effects. It was proposed to complement the ATW method with an additional forging phase early after pouring the molten metal in the mold, WRIST [19], to reduce the width of the fusion zone, FZ, + HAZ, and thus improve the track quality. The aim is to achieve this without magnifying detrimental residual stresses and further reducing the weld's fatigue life.

\subsection{Present investigation}

The ATW process is simulated in detail in a sequential thermal-mechanical FE analysis, covering all phases of the process as presented in Fig. 1 (i.e., preheating, tapping, pouring of molten metal, cooling, and shearing of excess material). The FE software ABAQUS is used for the simulations. The influence of applying the additional forging pressure on the rail, after pouring the weld, on the residual stress field in the near weld area, the microstructure (and resulting hardness obtained in the weld metal and HAZ) and the width of the FZ + HAZ in the rail are studied. Simulated results for the temperature and stress fields are compared with results from the literature for the temperature field after preheating and welding, Banton [20]. For the width of the HAZ, simulated results and metallurgical examinations are compared with Chen et al. [2].

Also, the FE-calculated residual stress field for the ATW process is compared with experimentally determined residual stress fields for the ATW method, and for numerically and experimentally determined stress fields for the FBW method.

\subsection{Finite element model set-up}

An experimental set-up of the ATW process that was followed by Goldschmidt Group (GG) was studied in the present paper, see Fig. 2. The position of supports and the mold is indicated. This new method, developed by GG see WRIST [19], was proposed to reduce the width of the FZ + HAZ. To achieve this, the rail is pressed into the hot weld metals by the ALFONS (ALigning, FOrging and Shearing) module, early in the cooling stage, shortly after pouring of molten metal. The additional forging provided by ALFONS is applied to the web of the rail. This is modeled by a prescribed nodal displacement as shown in Fig. 2.

The rail profile and material considered correspond to that of UIC60 (CSN EN 13674-1 + A1. Railway applications Track - Rail - Part 1: Vignole railway rails $46 \mathrm{~kg} / \mathrm{m}$ and above) and pearlitic R260 grade steel, respectively. The chemical composition and mechanical properties of R260 are shown in Table 1.

The mold geometry was provided by GG (WRIST [19]). The total weight of the ALFONS module was estimated as $850 \mathrm{~kg}$ and assumed to be evenly distributed over a length of $887 \mathrm{~mm}$. The rails are modeled as placed horizontally in the welding frame. The crowning angle $\left(3^{\circ}\right)$ used in the set-up for the rails was not modeled. Moreover, the weld gap $25 \mathrm{~mm}$, or $12.5 \mathrm{~mm}$ for one rail, was used in the FE simulations.

Note that Fig. 2 presents a planar view of the longitudinal plane that splits the geometry in half, and that due to symmetry, only half of this planar view is shown. This means that only a quarter of the total model needed to be studied. 
Fig. 2 Experimental setup for conventional ATW, and for ATW with additional forging pressure (ALFONS)

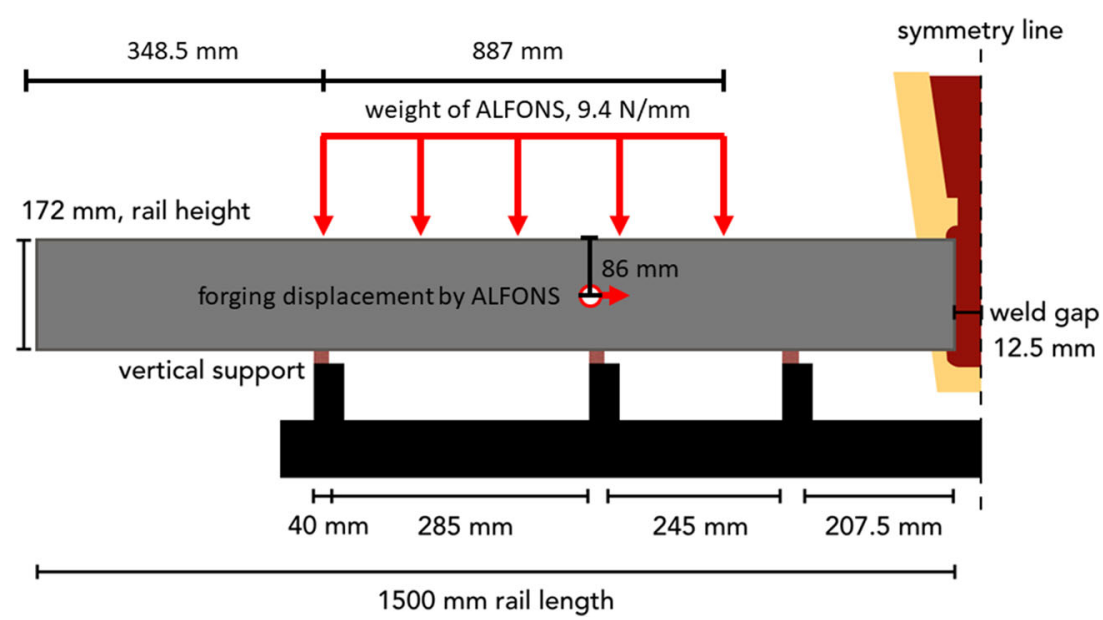

Preliminary simulations indicated that the molds, which are core shooted sodium silicate-bonded sand forms, did not need to be included in the model. The mold can be considered both as insulator, in the thermal analysis, and a boundary condition that restricts the molten weld metal to move in a certain direction (in the channels to the gap between the rails). The preliminary simulations also showed that the weight of the rail, mold, mold shoes, and reaction crucible with thermite mixture did not need to be included in the analysis. The stiffness and the mechanical strength of the sand are very low and do not contribute to the build-up of stresses in the weld metal and rail. Therefore, the 3D FE model only considered the rail(s) and the channels in the mold where the weld metal (thermite) is poured.

\subsection{Thermal and mechanical boundary conditions and loads}

\subsubsection{Symmetry}

As mentioned above, there are two symmetry planes: along the length of the rail, the geometry is split in half by a vertical symmetry plane, whereas a second symmetry plane is assumed across the weld gap. These symmetry planes are taken as insulated surfaces in the thermal FE model. In the

Table 1 Chemical composition and mechanical properties for R260 grade steel

\begin{tabular}{llllll}
\hline \multicolumn{7}{l}{ R260 composition (liquid) \% by mass [21] } \\
$\mathrm{C}$ & $\mathrm{Mn}$ & $\mathrm{Si}$ & $\mathrm{P}(\max )$ & $\mathrm{S}(\max )$ & $\mathrm{Cr}(\max )$ \\
$0.62-0.80$ & $0.70-1.20$ & $0.15-0.58$ & 0.025 & 0.025 & 0.15 \\
Mechanical properties & & & & \\
\multicolumn{7}{l}{$\begin{array}{l}\text { Tensile strength (MPa) [18] } \\
880\end{array}$} & \multicolumn{4}{l}{ Yield strength (MPa) [10] } \\
\hline
\end{tabular}

mechanical FE model, there is no displacement through the symmetry planes.

\subsubsection{Convection}

The free surfaces of the structures are defined as those that are in direct contact with the surrounding air, resulting in an exchange of energy through natural convection. The heat transfer coefficient $h$ for these surfaces is taken from Chen et al. [2] as $h=7 \mathrm{~W} / \mathrm{m}^{2} \mathrm{~K}$, and the ambient temperature was set to $18{ }^{\circ} \mathrm{C}$. The ambient temperature used was taken from the experiments, Banton [20] used to calibrate in the simulations to the measured temperatures. Heat transfer by radiation was neglected as it will take place during a very short time when heat conduction is dominating the heat transport.

In Banton [20], temperatures were recorded in the rail at the distance $10 \mathrm{~mm}$ from the rail end at several positions in the vertical direction on the rail (running surface, field face, web (fishing surfaces and center web), and foot) during the preheating, pouring, and cooling phases of thermite welding using the Thermit welding SkV-E process. Type K glass insulated thermocouples positioned in a $3-4 \mathrm{~mm}$ deep slot in the surface of the rail and covered with a ceramic putty for protection were used for the temperature recordings.

The three vertical supports, where the surfaces of the rail are in direct contact with the welding frame, see Fig. 2, are assumed to act as heat sinks, i.e., they extract energy from the structure. This is modeled with a convective boundary condition, with the heat transfer coefficient $h$ taken as $h=13 \mathrm{~W} /$ $\mathrm{m}^{2} \mathrm{~K}$ and an ambient temperature of $18^{\circ} \mathrm{C}$. Furthermore, the possible heat sink provided by the contact points on the rail web where the prescribed displacement is achieved is not modeled in the thermal model.

As the mold is not included in the FE model, the heat exchange between the weld metal and mold, as well as between the rail and mold, were approximated with a heat transfer coefficient $h=13 \mathrm{~W} / \mathrm{m}^{2} \mathrm{~K}$ and an ambient temperature of 
Fig. 3 Left, convective surfaces; highlighted in red, model the heat transfer between the weld metal and mold; mid and right, new free surfaces and convective boundaries after material has been removed by a shearing device

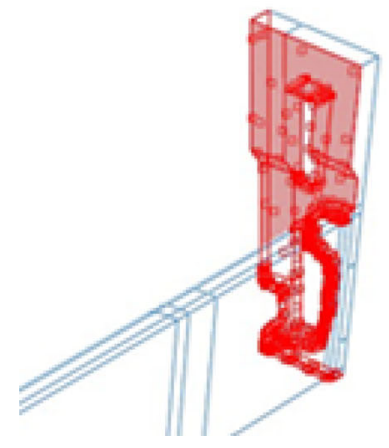

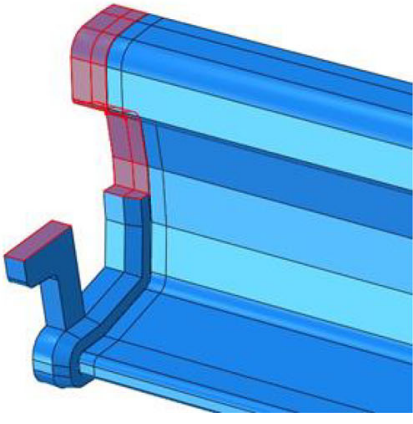

Internal free surface

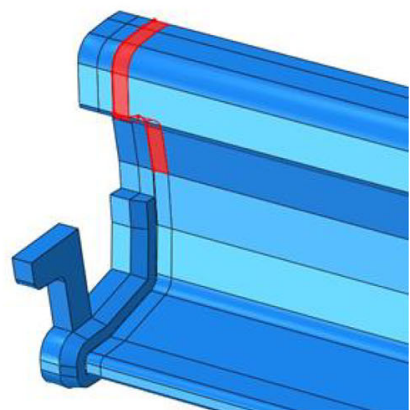

External free surface $18^{\circ} \mathrm{C}$. These convective surfaces in the $3 \mathrm{D}$ model can be seen in Fig. 3. In the shearing step of the ATW process, see Fig. 1, excess material is removed by a hydraulic shearing device. This results in new material being exposed to the surrounding environment, see Fig. 3. This is modeled by redefining the free surfaces, as is shown in Fig. 3. In this area, the heat transfer coefficient $h$ is taken as $h=13 \mathrm{~W} / \mathrm{m}^{2} \mathrm{~K}$ and the ambient temperature $18{ }^{\circ} \mathrm{C}$. For both cases, the mold and the sheared off surfaces, the value for $h$ was calibrated with results from the experiments by Banton [20].

\subsubsection{Vertical support}

The rail is assumed to be supported by a welding frame, see Fig. 2. This boundary condition is modeled as the rail being simply supported at the three vertical supports.

\subsubsection{Prescribed forging pressure (ALFONS module)}

The forging, as enforced by the ALFONS module, is modeled by linearly increasing the horizontal displacement at a single node at a certain time after pouring of the weld metal, see Fig. 2, to a certain magnitude, and then deactivating the same boundary condition.

\section{Material model}

\subsection{Thermal properties}

The FE model includes two different materials, the R260 grade rail steel for the rail and weld metal. They are assumed to have the same thermal and mechanical properties. The thermal properties for the R260 steel are estimated from Tuchkova [22]. Fig. 4 shows the density, thermal conductivity, and heat capacity variation with temperature. Note that the convection within the liquid pool was approximated by artificially increasing the conductivity above the melting temperature ( $T \geq T_{\text {liq }}=1465^{\circ} \mathrm{C}$ ) by a factor of five, see Chen et al. [2].

\subsection{Latent heat and phase transformations}

The effect of phase transformations has been accounted for in the thermal analysis by defining a latent heat that models large changes in internal energy due to phase changes of the material. The phase transformation, from liquid to solid, takes place at $T_{\text {liq }}=1465{ }^{\circ} \mathrm{C}$ and $T_{\text {sol }}=1380{ }^{\circ} \mathrm{C}$, see for example Tuchkova [22], with the total internal energy associated with the phase change corresponding to $277 \mathrm{~kJ} / \mathrm{kg}$. The start and end of the austenite to pearlite phase transformation is approximated from CCT diagrams for R260 to be $T_{\mathrm{s}}=700{ }^{\circ} \mathrm{C}$ and $T_{\mathrm{f}}=660^{\circ} \mathrm{C}$. For this case, the specific heat is estimated to $2 \mathrm{~kJ} /$ $\mathrm{kgK}$, see Chen et al. [2] which will give the internal energy $80 \mathrm{~kJ} / \mathrm{kg}$.

\subsection{Mechanical properties}

Assuming that the deformation field may be decomposed into individual components, the strain increments can be expressed with a small strain notation as follows:

$\Delta \varepsilon=\Delta \varepsilon^{\mathrm{e}}+\Delta \varepsilon^{\mathrm{p}}+\Delta \varepsilon^{\mathrm{th}}$

where $\Delta \varepsilon^{\mathrm{e}}, \Delta \varepsilon^{\mathrm{p}}$, and $\Delta \varepsilon^{\mathrm{th}}$ denote elastic, plastic, and thermal strain changes, respectively. Visco-plastic and creep strains may be neglected as the time spent at higher temperatures is relatively short. To reduce the computational cost, material sections that are not of primary interest, i.e., rail sections far from the fusion zone (FZ), are taken as elastic during the ATW process. No significant temperature gradients or plastic yielding can be expected to occur in these areas.

Fig. 4 a Density, conductivity, and heat capacity variation with temperature estimated from Tuchkova [22]. b Temperature dependence of Young's modulus $E$ (left) and Poisson's ratio $\nu$ (right) estimated from Skyttebol and Josefson [10]. c Temperature dependence of yield stress and hardening modulus, from Skyttebol and Josefson [10]. d Thermal expansion coefficient for the rail and weld metal during heating and cooling. From Ahlström [23] 


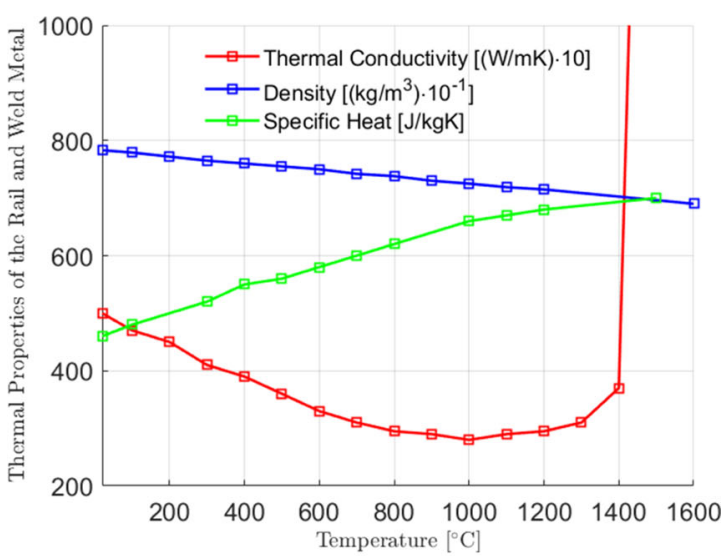

a Density, Conductivity and heat capacity variation with temperature estimated from Tuchkova [22].

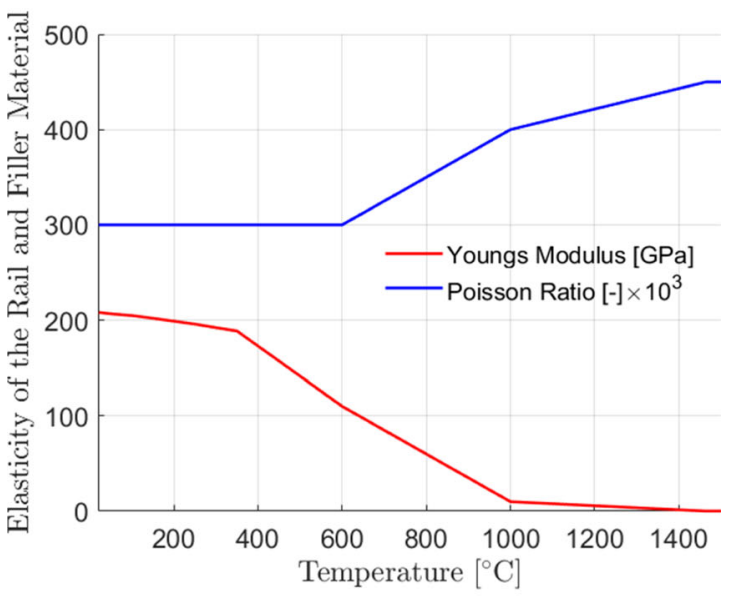

b Temperature dependence of Young's modulus $E$ (left) and Poisson's ratio $v$ (right) estimated from Skyttebol and Josefson [10].

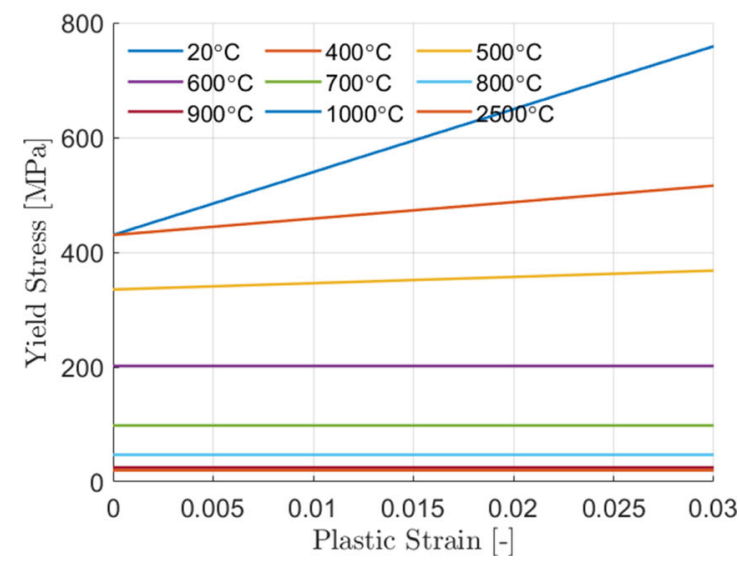

c Temperature dependence of yield stress and hardening modulus, from Skyttebol and Josefson [10]. 


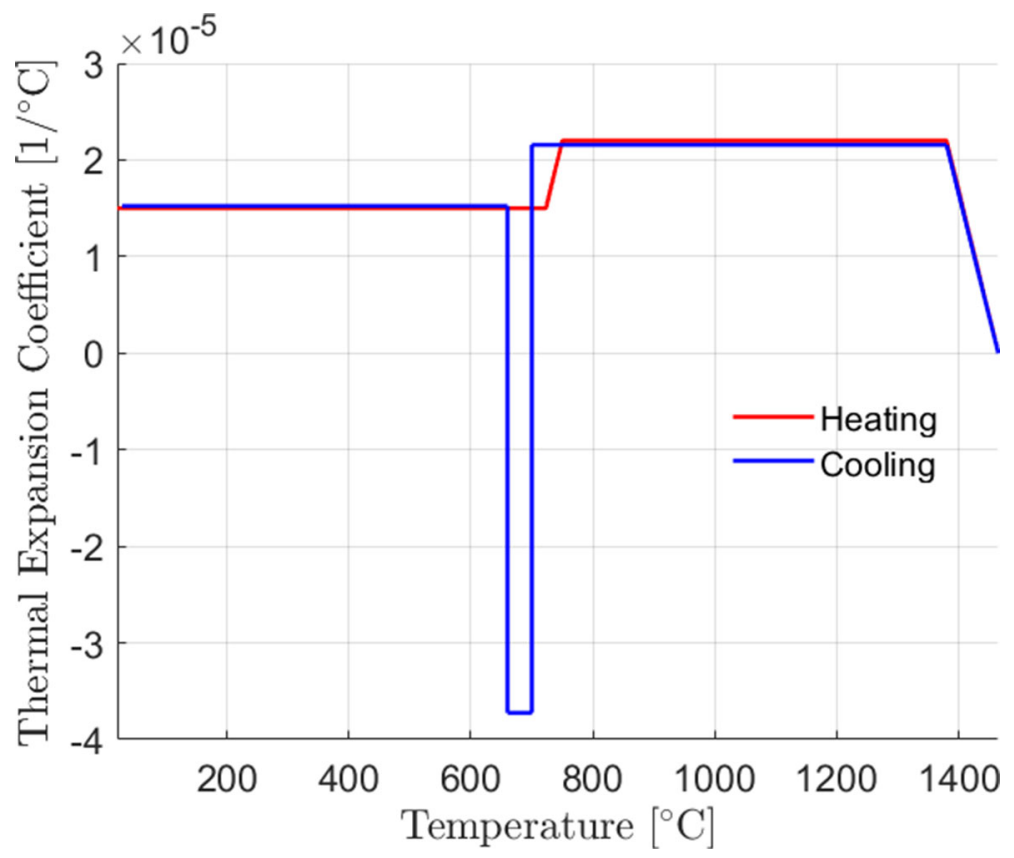

d Thermal expansion coefficient for the rail and filler material during heating and cooling. From Ahlström [24].

Fig. 4 (continued)

\subsection{Elastic material behavior}

The rail and weld metals are assumed to be isotropic elastic material with the Young's modulus $E$ and the Poisson's ratio $\nu$ values taken from Skyttebol and Josefson [10]. Figure 4b shows the temperature dependence of $E$ and $\nu$.

Note in Fig. $4 \mathrm{~b}$ that the stiffness decreases with increasing temperature, meaning that the material softens. However, the lower limit for $E$ at higher temperatures is uncertain due to limited experimental data for high temperatures. Here, the minimum value was chosen as $100 \mathrm{MPa}$ at temperatures above $1000^{\circ} \mathrm{C}$. This value is supported by limited experimental results from the literature [22].

The Poisson's ratio increases toward a magnitude of 0.5 as seen in Fig. 4b. However, to avoid numerical problems with an incompressible material, this value cannot be taken as too close to 0.5 .

\subsection{Plastic material behavior}

The yield stress and hardening at room temperature and at $600{ }^{\circ} \mathrm{C}$ have been determined in-house, see Skyttebol and Josefson [10]. The further temperature variation of the yield stress is taken to match the one in Eurocode (EN 93-1-1 Eurocode 3: Design of steel structures - Part 1-1: General rules and rules for buildings). The rail and weld metals are modeled using linear isotropic hardening, as the ATW process only includes limited reversed yielding at lower temperatures; though cyclic experiments of rail R260 are limited, Skyttebol and Josefson [10] show that kinematic hardening, or rather nonlinear kinematic hardening may be a better representation. The temperature variation of the yield stress and the hardening modulus is shown in Fig. 4c.

At higher temperatures, the material is considered elastic ideally (perfectly) plastic. Moreover, at these temperatures, available data is scarce, see above. Here a lower limit value of the yield stress is taken as $25 \mathrm{MPa}$ for temperatures above $1000^{\circ} \mathrm{C}$, which also has support from limited experiments in the literature, Lindgren [24].

When the material cools after pouring, it will be subject to solid state phase transformations, from austenite to pearlite, as discussed below. It is assumed that the hardening measure, i.e., the effective plastic strain, accumulated in an earlier phase will not affect hardening in the new phase. Hence, the accumulated effective plastic strain is reset at a certain temperature, here chosen as $700{ }^{\circ} \mathrm{C}$, using the ABAQUS annealing function.

\subsection{Volume changes during phase transformations}

The thermal expansion of pearlite and austenite during heating and cooling respectively follows Ahlström [23] and is shown in Fig. 4d. The volume expansion seen during the transformation from austenite to pearlite (during rapid cooling) is modeled by a corresponding decrease of the thermal expansion coefficient in the temperature interval of the phase 
transformation. However, the volume change at the transformation from pearlite to austenite during heating is not considered in this FE model. It is believed to have a minimal effect on the behavior after pouring of the weld metal and may thus be neglected.

In ABAQUS, the increment of the secant thermal strain $\Delta \varepsilon^{\text {th }}$ is, by default, computed as follows:

$\Delta \varepsilon^{\text {th }}=\alpha(T) \cdot(T-$ Tref $)-\alpha($ Tin $) \cdot($ Tin-Tref $)$

where $\alpha, T, T_{\text {ref }}$, and $T_{\text {in }}$ are, respectively, the coefficient of thermal expansion, the temperature, the reference temperature, and the initial temperature. During the preheating phase, the reference temperature is set to $18^{\circ} \mathrm{C}$, for all elements, including the (then silent) weld metal. For the following stages, i.e., tapping and pouring phases, when molten material is poured into the mold and comes into contact with heated rail ends, this formulation cannot be used. Moreover, the FE analysis had to be divided into separate analyses when using ABAQUS.

For the tapping and pouring phases, the thermal strain increment for the supplied molten metal (and for the material at the rail ends that melt during pouring) is computed explicitly with a user subroutine in ABAQUS. This routine computes the secant thermal expansion increment as follows:

$\Delta \varepsilon^{\text {th }}=\alpha(T) \cdot \Delta T$

The reference temperature of the supplied molten material is taken as the temperature it has when it is filled into the weld gap, see for example Lindgren [24]. Here, this temperature is taken at the melting temperature $1465{ }^{\circ} \mathrm{C}$. This also means that the volume changes experienced when the weld metal solidifies are assumed to take place in the upper part of the mold above the weld gap.

\subsection{Finite element simulation procedure}

As mentioned above, the ATW process is simulated as a sequentially coupled thermomechanical analysis. Thus, two different analyses are set up, one thermal analysis and one mechanical analysis. The temperature field calculated in the thermal analysis is imported into a mechanical analysis as a load. The coupling term in the thermal analysis (relating to the plastic strain) is normally very small in welding problems and can be neglected. Moreover, the effect of the deformation field on the thermal boundary conditions is believed to be unimportant here, as large deformations are unlikely to occur where these boundary conditions are found.

The commercial software ABAQUS version 6.14.2 was used in the FE simulations using a large displacement, large strain formulation. Linear brick elements, DC3D8 (thermal) and C3D8R (mechanical), were used for the rail, whereas linear tetrahedral elements, DC3D4 (thermal) and C3D4 (mechanical), were used for the weld metal part. Note though that brick elements were used in the weld metal part where the cross section of the thermite corresponds to that of the rail. The mesh is refined in the weld metal region and close to the rail end. The same mesh is used for both thermal and mechanical fields. In total, 282,824 elements resulting in 643,539 degrees of freedom were used, based on a convergence study for a simpler two-dimensional model.

Figure 5 summarizes the different steps of a conventional ATW process as simulated using ABAQUS. Due to the addition of new material during the pouring step, the process had to be divided into three different simulations, and results transferred between simulations using an import option in ABAQUS. One may note though that in the thermal FEA, the pouring and shearing/cooling simulations are combined into one simulation. For the case of additional forging, see Fig. 2, an additional prescribed displacement is applied in the third shearing and cooling analysis.

\subsection{Preheating and tapping step}

In the first step, an oxy-propane torch is positioned above the rail head during the initial phase of ATW to dry and clean mold and rail interface to reduce the risk for gas pores inside the weld and to slow down cooling rates. This is modeled by prescribing a heat flux to the free rail surfaces inside the weld gap for a time period of $180 \mathrm{~s}$ ( $3 \mathrm{~min})$. The procedure follows experiments, Banton [20], where temperatures were recorded at different locations of the rail surface, $10 \mathrm{~mm}$ from the rail end, on the rail head (running surface, field face), web (fishing surfaces and center web), and foot.

The energy input by the preheating torch is modeled as two distributed heat fluxes that act on the rail interface and running surface. These fluxes are assumed to vary with time, rail height, and width. They have been determined by computing the difference between experimental temperatures from Banton [20] and the FE calculated temperatures in corresponding points. This difference is minimized using a least squares fit (the fminsearch function in MATLAB). During the tapping period, some $55 \mathrm{~s}$ (1 $\mathrm{min}$ ), the heat flux is stopped and the rail cools while a crucible is attached on top of the mold.

During the preheating and tapping phases, the weld metal is included for the analysis to be consistent with later simulations and to assign horizontal symmetry boundary conditions in this phase so that rigid body motion is prevented. The weld metal is a silent material, i.e., it is given a very low stiffness and yield strength, to ensure that it has no effect on the behavior of the rail until it is activated in the pouring stage.

\subsection{Pouring step}

In this step, the temperature in the weld metal is increased, in $1 \mathrm{~s}$, to $750{ }^{\circ} \mathrm{C}$, which is the temperature of the rail end at the 
Fig. 5 FE Simulation procedure for conventional ATW

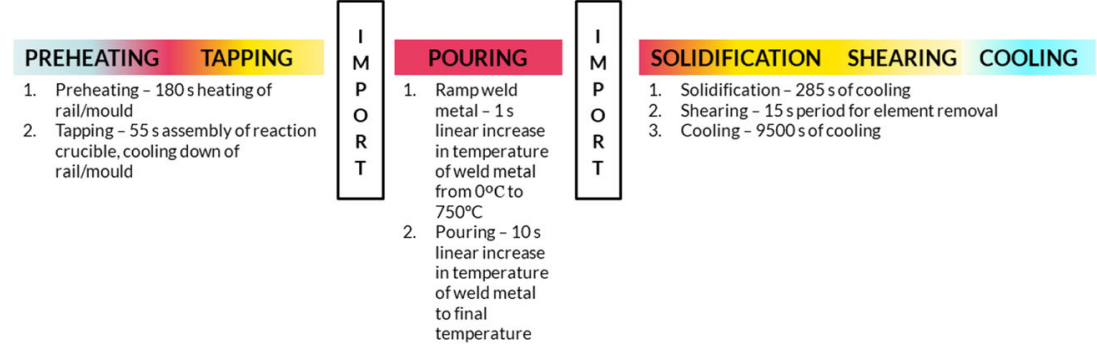

end of the preheating and tapping step. The pouring of a liquid is modeled by increasing the temperature of the weld metal to a spatial distribution valid when pouring is finished. The molten, weld metal material has a temperature of some $2050{ }^{\circ} \mathrm{C}$ in the crucible above the mold but cools, still being a fluid, when flowing down into the channels of the mold and then up into the weld gap. Here, this spatial variation of the temperature at the instant of pouring was prescribed to follow the calculated spatial variation in Tuchkova [22]. Note that this means that pouring is assumed to occur in a very short time and that the entire weld metal column is considered from the start of this step. In this step, the weld metal has its material parameters changed to that of the rail. To prevent a significant amount of volumetric expansion when the temperature in the weld metal is continuously increasing, the thermal expansion of the weld metal is set to zero in this step.

\subsection{Shearing and cooling step}

When the pouring step is completed, the rail and weld metal will cool down. The thermal strain for the weld metal is reset, see Eq. (3) to model that it is now cooling from a melted state. This is done also for parts of the rail end, which melts during the pouring step. After some time, excess material is removed by a hydraulic shearing device. This is modeled by deleting elements modeling the weld metal, see Fig. 3, and by redefining the free surfaces for the convective boundary conditions, and continuing with the cooling process. The shearing as such is assumed not to introduce additional stresses. For the case of the use of an additional forging pressure, the ALFONS module, a prescribed displacement of $6 \mathrm{~mm}$, is applied on the rail web at a certain distance from the rail end, see Fig. 2, $120 \mathrm{~s}$ ( $2 \mathrm{~min}$ ) after pouring is completed. After a further $30 \mathrm{~s}$ ( $2 \mathrm{~min}$ and $30 \mathrm{~s}$ ), the displacement is deactivated.

\subsection{Thermal analysis of the ATW process: results}

The FE calculated temperatures and recorded temperatures provided by Banton [20] at the considered data points at the preheating and tapping stages are shown in Fig. 6. The time when preheating ends is indicated in Fig. 6. This result shows that the energy input model is sufficiently accurate at modeling the effect of the preheating torch at most of the points considered. Also note the large difference in maximum temperatures at the running surface and the field face.

For the pouring phase, the temperature of the weld metal, and the material in the rail end, is increased to that shown in Fig. 7a as an initial condition. Thereafter, the thermal boundary condition is deactivated and heat transfer between the different sections is possible, resulting in a more physical distribution of heat that is comparable to that calculated using CFD by Tuchkova [22]. Figure $7 \mathrm{~b}$ shows the temperature distribution $17.5 \mathrm{~s}$ ( $0.3 \mathrm{~min})$ after the boundary conditions have been deactivated. Figure $7 \mathrm{c}$ shows the temperature field once the material has cooled down for a significant amount of time (almost at room temperature).

Figure 8 shows calculated temperatures at different points $10 \mathrm{~mm}$ from the rail end, compared with measured temperatures from experiments, Banton [20]. The time for the shearing of excess material is indicated in Fig. 8. Overall, a good agreement with experimental results is achieved. Note that the effect of shearing of the material inside the mold may be seen at the running surface and field face nodes. As the material is removed, these nodes are directly exposed to the surrounding air, resulting in an increased cooling rate.

\subsection{Mechanical analysis of the ATW process: results}

The development of strains and stresses was simulated following the steps discussed above, see Fig. 5. Figure 9 shows the calculated vertical (S22) and longitudinal (S33) stresses in the rail and weld metal immediately after pouring, i.e., when the weld metal has been deposited and is still in molten form (but treated as a solid with very low stresses). One may note that after the tapping, the rail end is covered by the mold, which is not visible in Fig. 9 (but modeled with an insulating effect, see above). Although the temperature gradient from the molten weld metal into the rail is high, this part will have a temperature low enough to experience higher stress levels, which is also seen in parts further away from the mold higher where the temperature is some $700{ }^{\circ} \mathrm{C}$. Hence, the stress levels can be high and not limited by very low values for the yield stress.

Figure 10 shows the evolution of the vertical S22 and longitudinal S33 stress components with time at different locations for the conventional ATW process and for the ATW 

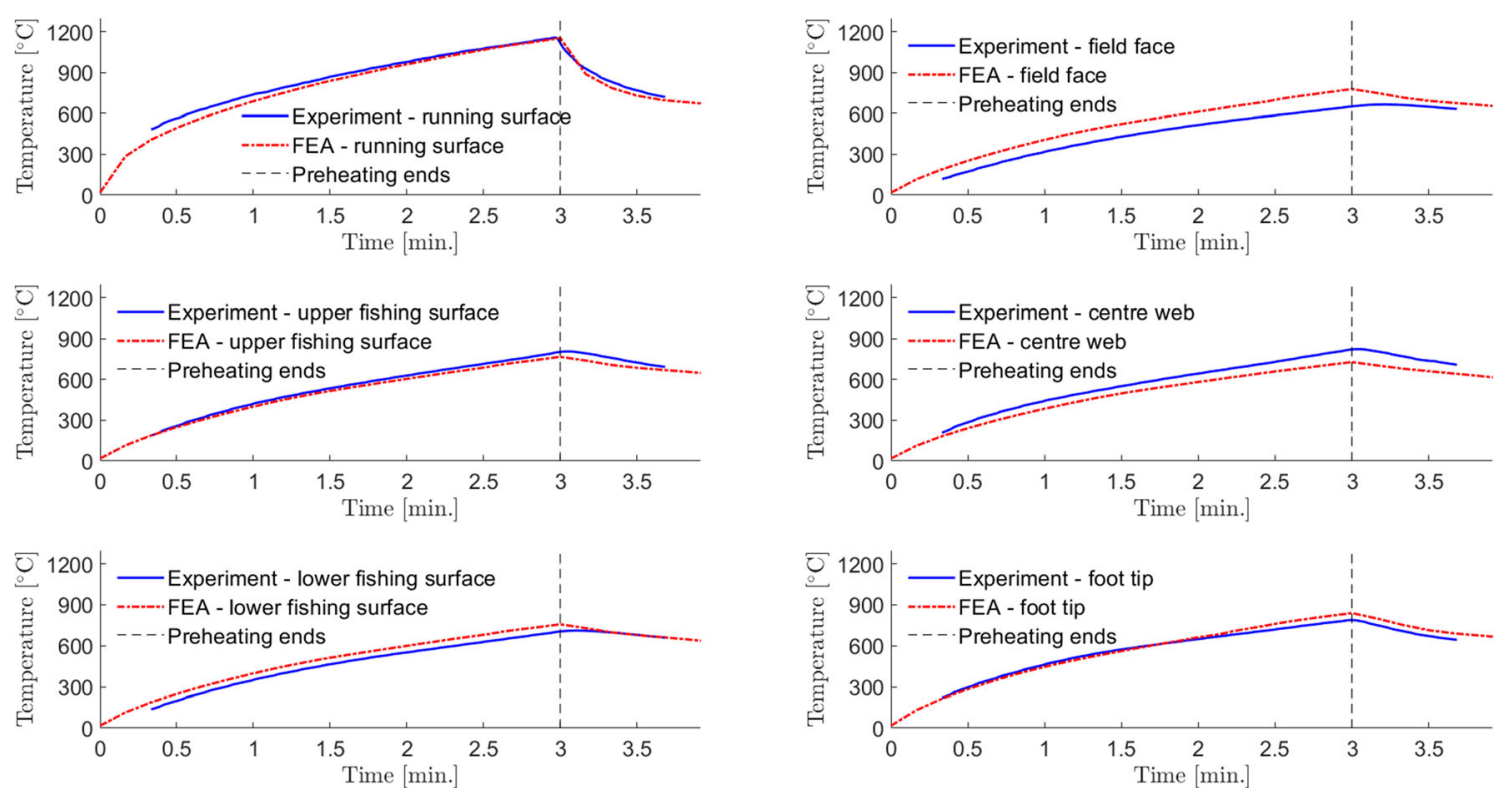

Fig. 6 Calculated and measured temperatures in rail $10 \mathrm{~mm}$ from rail end during the preheating and tapping stages. Time when preheating stops, $180 \mathrm{~s}$ (3 $\mathrm{min})$, is indicated

process with additional forging applied (the ALFONS module). The plots start when forging starts, i.e., $120 \mathrm{~s}(2 \mathrm{~min})$ after pouring, and lasts up until the end of cooling. Note that forging ends at $150 \mathrm{~s}$ ( $2 \mathrm{~min}$ and $30 \mathrm{~s})$. Note also that stresses
Fig. 7 Calculated temperature distribution when pouring starts (a), $17.5 \mathrm{~s}$ after pouring (b), and some minutes after pouring (c)

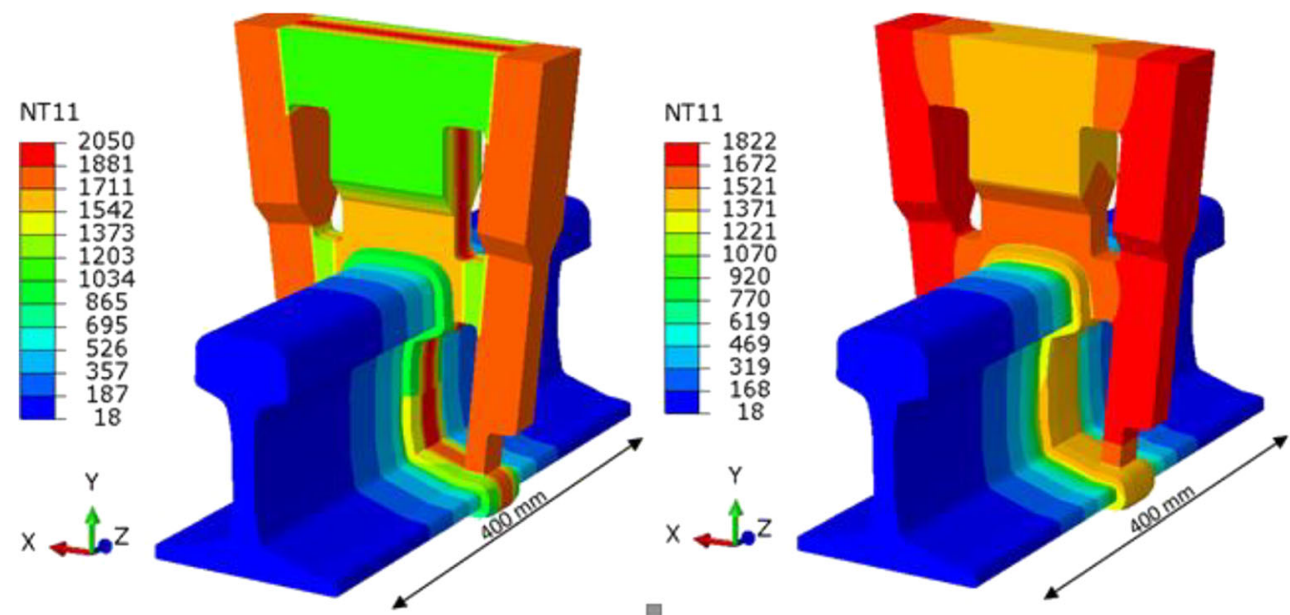

(a) After pouring

(b) 17.5 seconds after the end of pouring

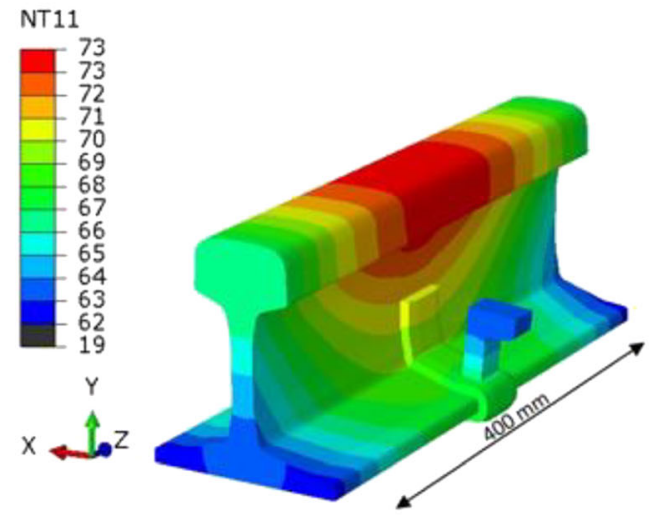

(c) At the end of cooling 

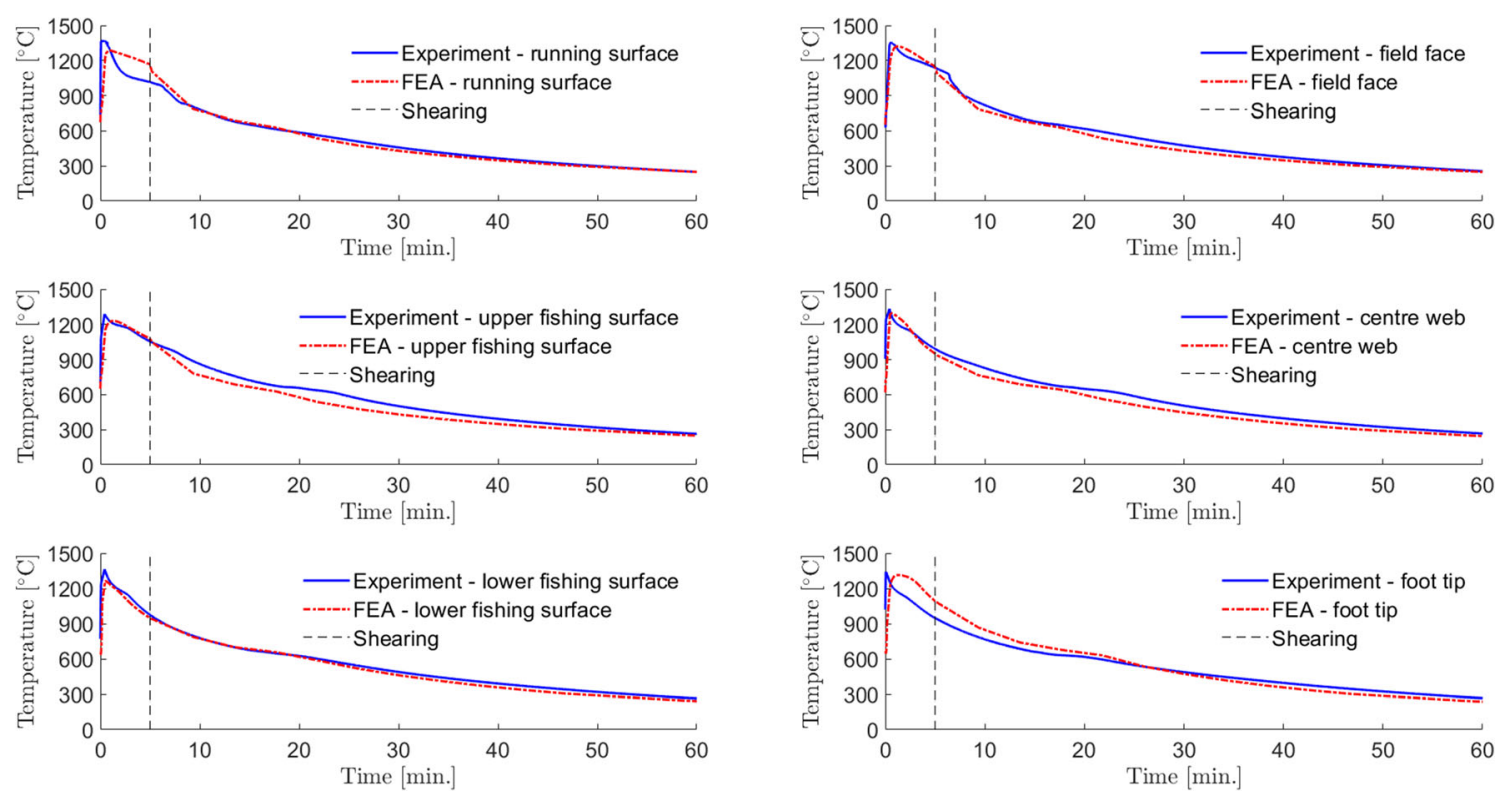

Fig. 8 Calculated and measured temperatures in rail $10 \mathrm{~mm}$ from rail end during cooling after pouring

in Figs. 10, 11, 12, and 13 are shown for weld metal within the rail profile (UIC60), i.e., stresses in the weld metal outside the profile that has not been sheared off (see Figs. 3 and 7c) are not shown. In general, the evolution for conventional ATW and ATW with ALFONS are similar giving qualitatively the same residual stress levels. Large tensile stresses are developed in the web in both vertical and longitudinal directions. The volume changes during the liquid-to-solid phase transformations, between $12 \mathrm{~min}$ and $18 \mathrm{~min}$, are shown as small stress variations, whereas the final phase transformation from austenite to pearlite will give a larger stress drop in both vertical (S22) and longitudinal (S33) components. This stress drop is recovered during the final cooling to room temperature. The difference in stress level when using ALFONS is similar for the transverse stress component (S11). However, as S11 will in general have lower magnitudes than S22 and S33, the change seen when using the ALFONS procedure will be relatively larger.

Figure 11 shows the corresponding evolution of the vertical (S22) and longitudinal (S33) stress components at different locations now with decreasing temperature during the cooling after pouring for the conventional ATW process and for the ATW process with additional forging applied (the ALFONS module). The plots start when forging starts, i.e., $120 \mathrm{~s}$ ( $2 \mathrm{~min})$ after pouring, and lasts up until the end of cooling. Note that forging ends at $150 \mathrm{~s}(2 \mathrm{~min} 30 \mathrm{~s})$. Note also that the final phase transformation from austenite to pearlite starts at the temperature $700{ }^{\circ} \mathrm{C}$ and ends at $660{ }^{\circ} \mathrm{C}$. In Fig. 11, the drop in stress components due to the volume increase at this phase transformation is clearly visible.

Figures 12 and 13 show the residual stress field in the rail and weld metal after cooling to room temperature. Both the

Fig. 9 Calculated vertical, S22, (left) and longitudinal, S33, (right) stresses $(\mathrm{MPa})$ in the rail and weld metal immediately after pouring
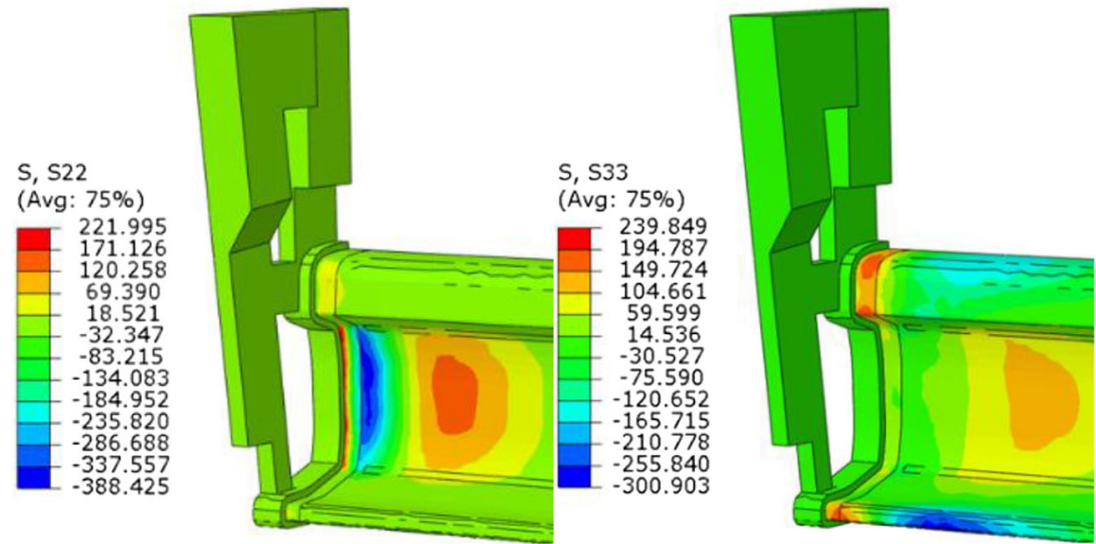
Fig. 10 Calculated development of stresses with time at weld center after pouring, forging starting 2 min (120 s) after pouring and ending at $2 \mathrm{~min} 30 \mathrm{~s}$ (150 s). Conventional ATW, left, and for the ATW process with additional forging (ALFONS module), right

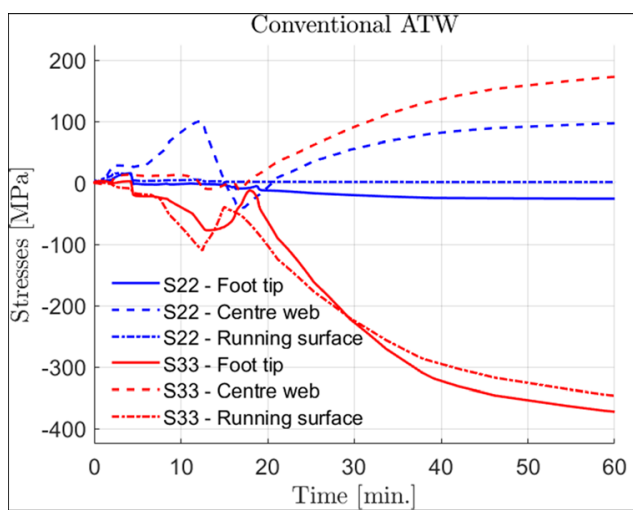

vertical (S22) and longitudinal (S33) stress components have large tensile values in the rail web close to the weld metal, and the longitudinal stress component also in the rail web weld metal. Introducing the ALFONS procedure will not change the residual stress field significantly, though the width of the tensile zone of the vertical stress (S22) seems to decrease somewhat. The transverse stress component (S11) is not shown, as it has lower magnitudes than the other two stress components. However, the transverse stress component (S11) has a high value inside the rail in the web-to-foot transition, possibly due to poor meshing in that intersection. This does not, however, affect the vertical and longitudinal stresses. The difference in the residual transverse stress (S11) after using additional forging (the ALFONS module) is also marginal.

Figure 14 shows the variation of the residual stress components through the thickness in the mid plane of the rail at the weld center line and at a distance $50 \mathrm{~mm}$ from the weld centre line (i.e., in the rail). As seen also above, there are only minor changes in the residual stress at these locations when additional forging is applied; the largest differences seen is at weld center in the lower rail head web interface. One finds also in the midplane of the rail large tensile vertical and longitudinal residual stresses in the web at the weld center and in the rail close to the weld metal. This is an area where cracks often initiate. For the longitudinal stress (S33), the tensile residual stresses in the web is balanced by compressive stresses at the running surface and at the rail foot. The transverse stress (S11) has lower values except possibly at the lower rail head upper web region. S11 also changes to a positive value on the running surface if ALFONS is used. This is possibly due to the large transverse plastic strains introduced during forging.

The calculated residual stress field can be compared with experimentally determined residual stress fields for thermite welds from Webster et al. [7] (using neutron diffraction), and partly Jezzini-Aouad et al. [8] (X-Ray diffraction) and Mutton and Soleileman [9] (using strain gauges). Good agreement with these references is observed, confirming the presence of high vertical stresses in the web and lower rail head and compressive longitudinal stresses in the rail head. As discussed above, FBW involves steps similar to those in ATW, so the residual stress field will be similar, which is seen in numerical and experimental investigations [10-13].

\subsection{Risk for formation of hot cracks}

Using the ALFONS module, a forging pressure is applied to the cooling weld metal and rails shortly after pouring (1$3 \mathrm{~min}$ ), i.e., when the material is still very warm. The
Fig. 11 Calculated development of stress with temperature after pouring at weld center. Conventional ATW, left, and for the ATW process with additional forging (ALFONS module), right
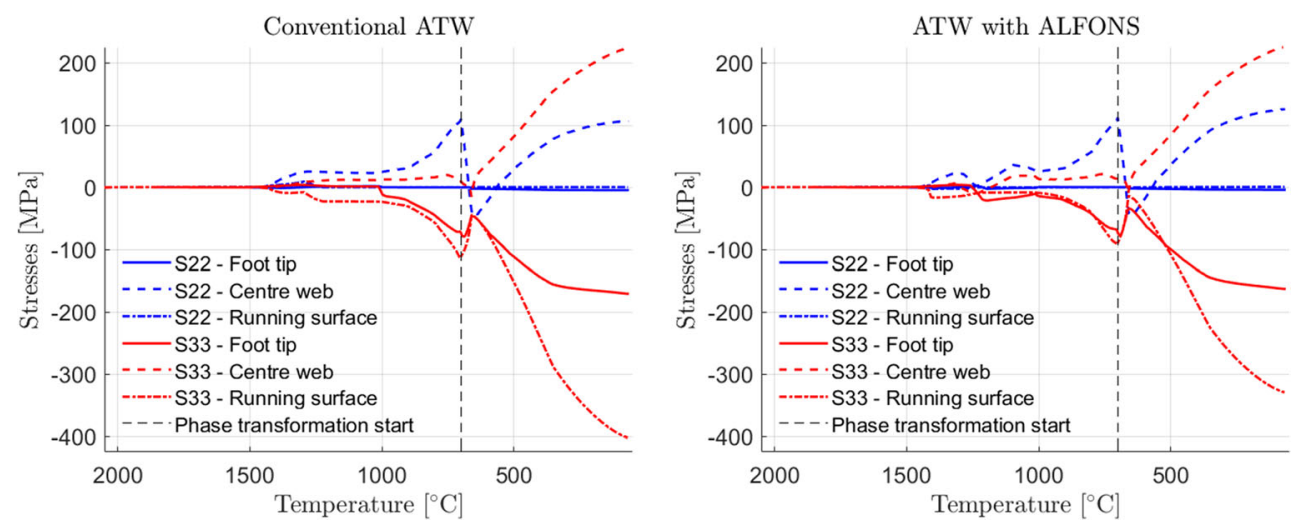
Fig. 12 Calculated residual stress (MPa) field after conventional ATW process. S22 is vertical and S33 is longitudinal stress component
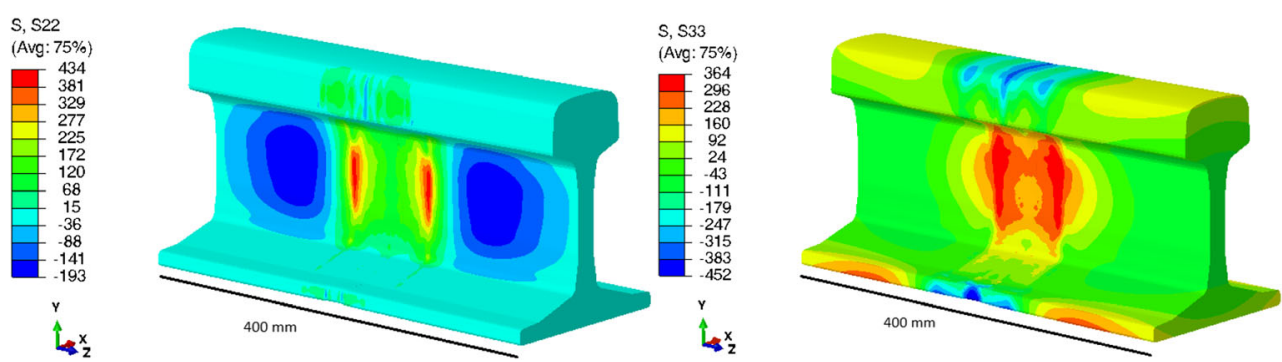

prescribed displacement corresponds to an average strain of some $1.3 \%$. This will push material into the weld metal, and it will result in large plastic deformations in this region. There is a concern that the risk for formation of hot cracks, i.e., cracks formed during the final solidification, is increased. At these high temperatures, when the material has just solidified, the knowledge of material behavior is limited. Also, the cooling rate is high. There are several proposed means of mechanically quantifying this effect of welding as caused by the material metallurgy. One measure of this risk for hot cracking is the change in mechanical strain, i.e., the sum of elastic and plastic strains, between two temperatures say $1450{ }^{\circ} \mathrm{C}$ and $1350{ }^{\circ} \mathrm{C}$, see $[25,26]$. Figure 15 shows the calculated change in the maximum principal mechanical strain during cooling between two temperatures, $1450{ }^{\circ} \mathrm{C}$ and $1350{ }^{\circ} \mathrm{C}$ for the case of additional forging starting $120 \mathrm{~s}$ ( $2 \mathrm{~min}$ ) after pouring, and lasting

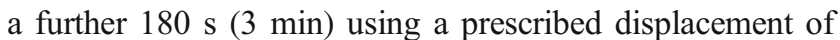
$6 \mathrm{~mm}$, left, and the corresponding situation during conventional ATW (right).

It is seen that this measure gives tensile values in the upper part of the web and lower part of the rail head with the additional forging applied. Hence, the upper part of the rail cross section, rail head and upper part of the web, seems to be sensitive to hot cracks. Hot cracks were found in a few of the tested welds at GTG at this location for the chosen combination of forging displacement and forging time. It was also found that forging earlier, or later, than the proposed $120 \mathrm{~s}$ ( $2 \mathrm{~min}$ ) after pouring, resulted slightly lower, or higher, plastic strains, respectively. One may note, see Fig. 10, that at the time for applying the forging pressure, there is a small tensile vertical stress in the web region. However, stresses are not used as a measure for crack formation, they are also a more uncertain measure due to the limited knowledge of material behavior at temperatures above $1000{ }^{\circ} \mathrm{C}$. It may also be stated that hot cracks did not appear when conventional ATW was carried out, as expected.

\subsection{Microstructure and hardness in weld and HAZ}

The microstructure of the rail after cooling may be estimated from the calculated cooling rates shown in Fig. 8 and the CCT diagram shown in Fig. 16. The CCT diagram has been constructed by JMatPro based on the chemical composition for the R260 steel grade in Table 1. One finds that the microstructure at the considered points will be fully pearlitic. The rail weld and HAZ of some welds were also examined metallographically to validate the predicted microstructure. Figure 17 presents optical microscopy images of weld microstructures from the center line of the weld to the parent material (R260) from the left to the right. It also compares the microstructural gradient induced by the conventional process to this generated by the additional forging. The metallographic examination was performed at two positions, the railhead and foot, according to the European standard EN 14730-01. Briefly, the procedure for the microscopic examination requires the inspection of the area $3-15 \mathrm{~mm}$ below the running surface and at the same distance from the tip of the rail foot. After mirror polishing, specimens were etched by $4 \%$ Nital. In all images, the dominant microstructure is the pearlitic structure which confirms the thermal FE analysis. Even with the additional forging, see Fig. $17 \mathrm{a}$ and $\mathrm{b}$, the scanning of the weld subregions does not show any presence of the unwanted phases such as martensite or bainitic. Similar microstructures are obtained in the FZ. It contains a pearlitic phase, in brown color,
Fig. 13 Calculated residual stress (MPa) field after conventional ATW process with additional forging added (ALFONS module). S22 is vertical and S33 is longitudinal stress component
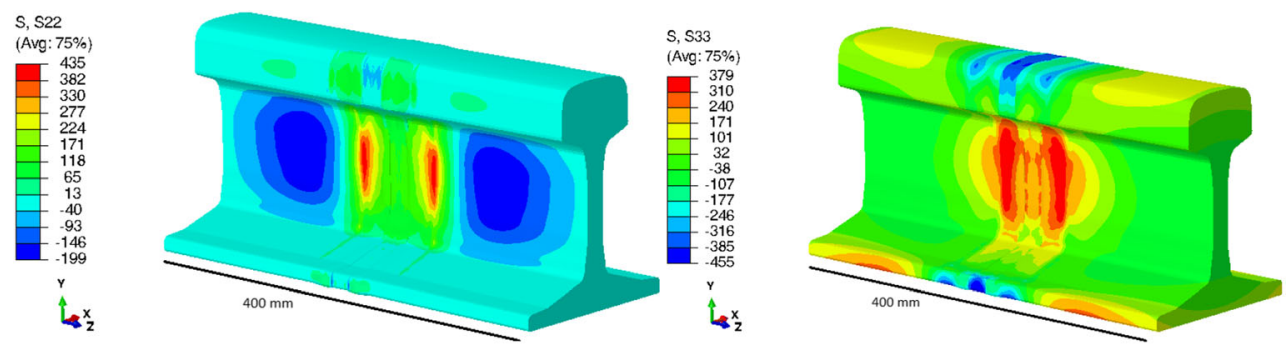
Fig. 14 Calculated variation of residual stress in the rail mid plane at the weld center (left) and at a distance $50 \mathrm{~mm}$ from the weld center line (right). $S 11$ is transverse, $S 22$ is vertical, and $S 33$ is longitudinal stress

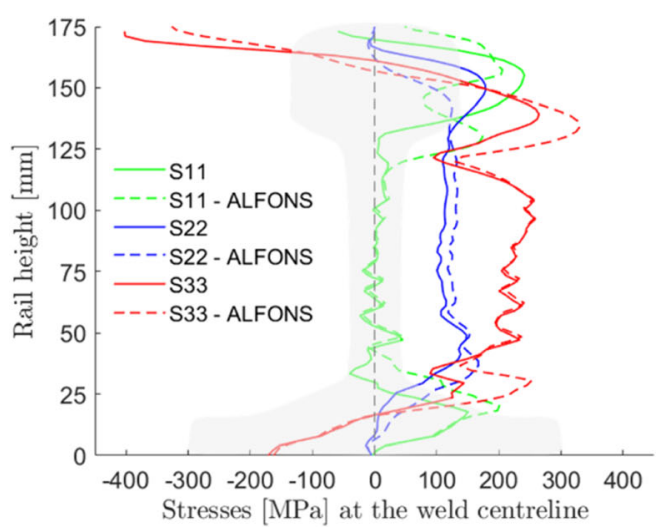

with proeutectoid ferrite (white color) formed around inclusions (black color) and along the grain boundaries. In some parts of the HAZ, within coarse grains, it is also possible to form proeutectoid ferrite.

In addition to showing a pearlitic structure, Fig. 17 also illustrates the microstructural gradient generated by the heat during welding. The area nearest to the FZ experiences a rapid and high temperature rise. This leads to grain growth and generates, after cooling, the coarse grain heat-affected zone sub-region. Far from the FZ, a re-crystallization process contributes to a visible decrease of grain sizes forming a second HAZ zone sub-region. The presence of the metallurgical subregions in the HAZ affects the hardness distribution.

\subsection{Hardness measurement through the weld}

Figure 18 shows the average of hardness distributions in the railhead, web, and foot of welds manufactured by the conventional ATW and with additional forging (the ALFONS module), respectively. Averages are calculated from three welds from each process. For conventional welds, shown for reference in Fig. 18a, the average shows that the high hardness in the rail web and foot are located at the same distance from the weld center. By comparison, the high hardness zone of railhead is slightly shifted, leading to a larger HAZ.
Concerning the additional forging case (the ALFONS module), hardness profiles have an asymmetrical distribution. The hardness seems to increase from the left side to the right in Fig. 18b. Also, the rail foot has the lowest hardness compared with the web and head. This contradicts the reference weld result, see Fig. 18a. One may note that non-symmetric profiles are observed also in individual welds made with additional forging. The cause for this asymmetric profile is unclear. There may be variations in the procedure for applying the prescribed displacements in the rail head, i.e., in the positioning of the cylinders creating the prescribed displacement and in the stability of the full machine during the forging, which could lead to the asymmetric hardness variation.

\subsection{Width of the heat-affected zone}

The width of the HAZ is an important measure in the WRIST [19] project, as reducing the width of the FZ and the HAZ is a primary objective of the project. Based on the hardness measurements above, the width of the HAZ can be estimated following the European standard 14370-01. Figure 19 shows the relationship between the gradient of the microstructure and the hardness variation across one side of the thermite weld, from the FZ to the parent material. Usually the fusion metal and parent materials have almost the same hardness. The hardness change occurs in the HAZ. According to the European
Fig. 15 Calculated change in maximum principal mechanical strain between temperatures $1450{ }^{\circ} \mathrm{C}$ and $1350{ }^{\circ} \mathrm{C}$ after ATW with additional forging (left) and after conventional ATW (right)
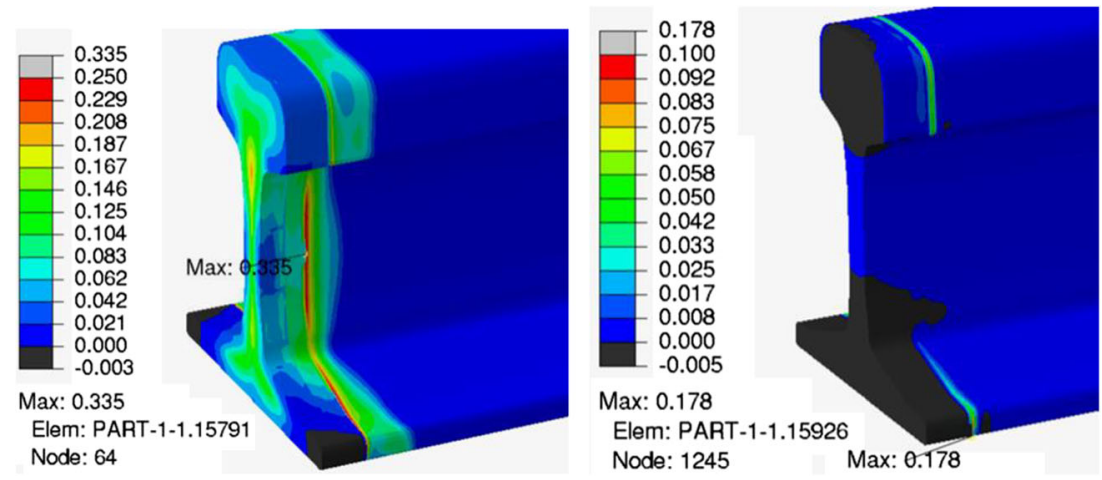


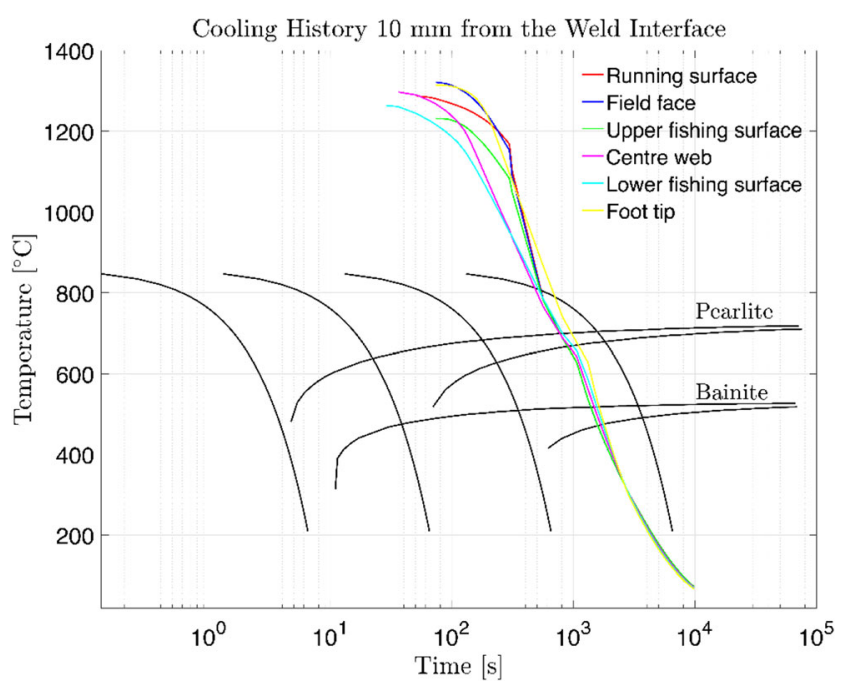

Fig. 16 Cooling curves for different points in rail cross section and CCT diagram for R260 steel (constructed by JMatPro)

standard, the length of the low hardness zone should not exceed $20 \mathrm{~mm}$, known as the heat-softened zone. The rail weld, Fig. 19, shows a softened width of some $16 \mathrm{~mm}$. The total length of the HAZ is the sum of the low hardness (LH) and the high hardness $(\mathrm{HH})$ widths, giving a total length about $33 \mathrm{~mm}$ for both cases, the conventional ATW or when using ALFONS.

The width of the FZ + HAZ has also been estimated from the FE simulations. The HAZ was then defined for nodes whose temperature has exceeded the eutectoid point of $723{ }^{\circ} \mathrm{C}$ at any point during the welding process, instead of using a definition based on hardness. Figure 20 shows the locations where the width has been calculated.

Table 2 gives the approximate FZ and HAZ width for conventional ATW and ATW with ALFONS (with the total prescribed displacement $12 \mathrm{~mm}$ ). As mentioned above, large plastic deformations will be introduced in the weld metal (FZ) during forging. During further cooling, additional plastic strains will be introduced in the weld metal and rail close to the weld. After cooling, there will be large residual plastic strains at the weld center (tensile in the transverse and compressive in the longitudinal direction) and at the interface to weld metal columns in the mold (later sheared off). The resulting reduction of the $\mathrm{FZ}$ width will be some $6 \%, 1 \mathrm{~mm}$,
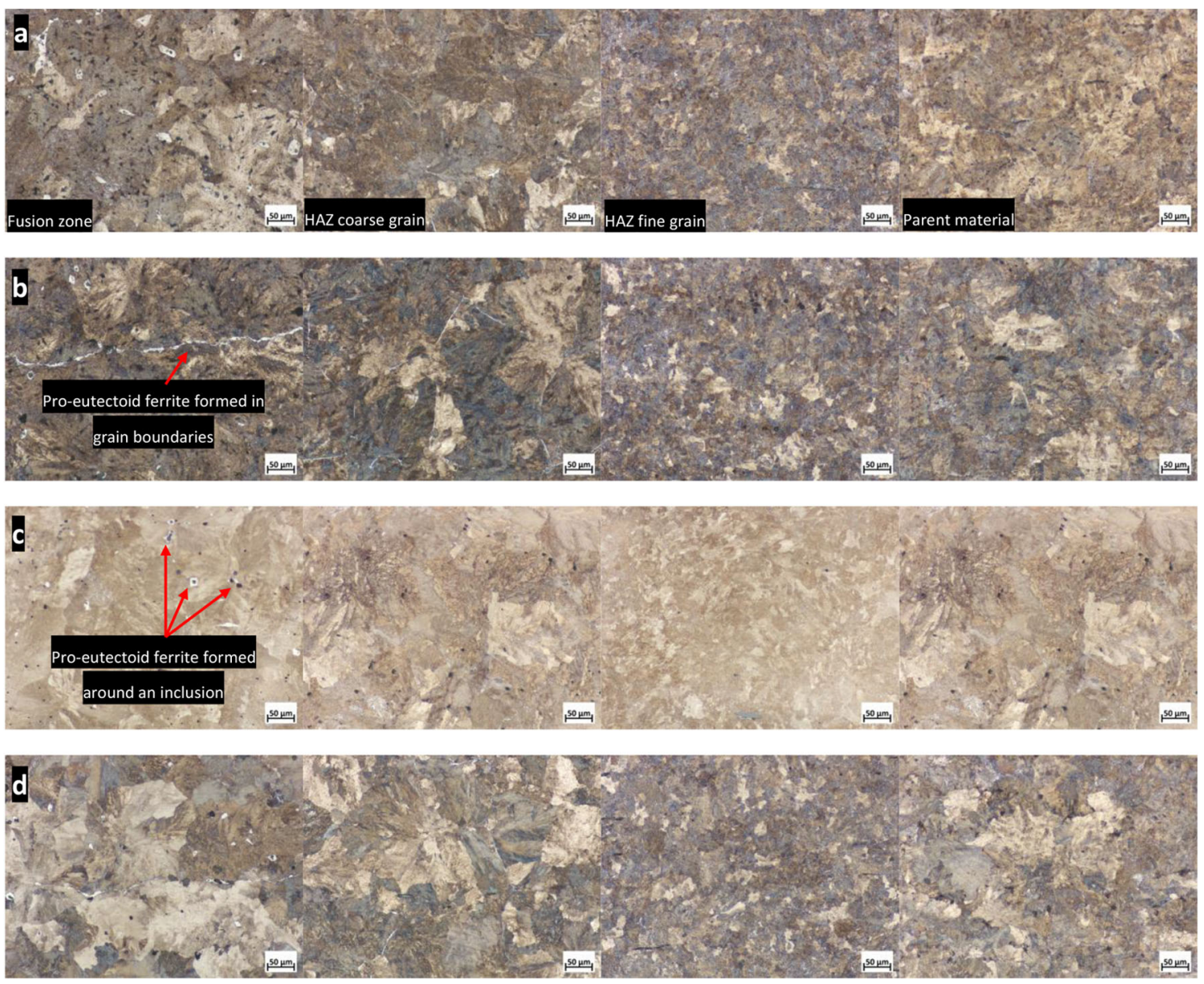

Fig. 17 Microstructural gradient induced by conventional ATW with additional forging. a Rail head. b Rail foot, conventional ATW. c Rail head. d Rail foot. 

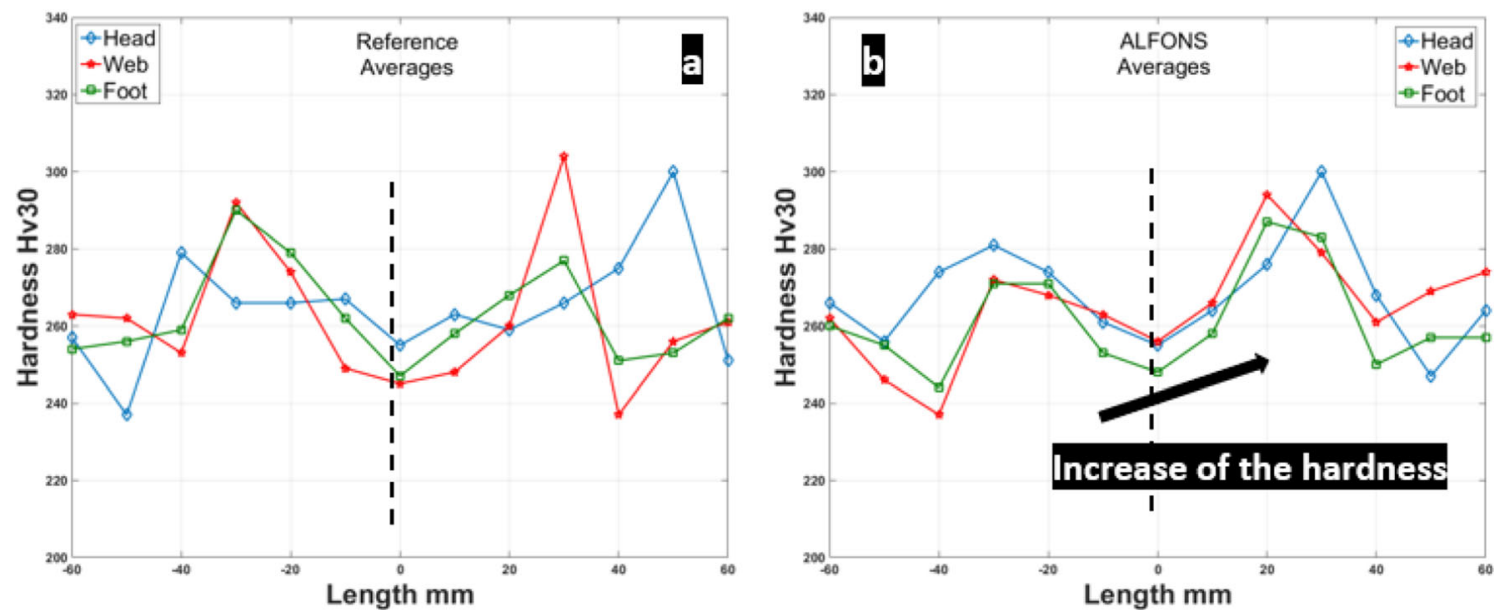

Fig. 18 Longitudinal hardness distribution in railhead, web, and foot as a function of welding process. a Conventional ATW welds. b ALFONS process welds (with additional forging)

(small) when ALFONS is introduced. It is also seen that the HAZ is marginally reduced. As the width of the HAZ in the rail is mainly determined by the heat input, which the same is when ALFONS is used, this difference for the HAZ is due to the plastic deformation of the rail material during the forging. Included in Table 2 is also an estimation of the corresponding widths of the HAZ based on the measured hardness profiles. The basis for a comparison differs somewhat as the weld gap used in the FE simulations was $25 \mathrm{~mm}$, see Fig. 2, whereas the weld gap used for the welds (produced in a later stage) examined in Figs. 18 and 19 was $50 \mathrm{~mm}$. It is seen also from the measured hardness profiles that use of additional forging may give a somewhat smaller width of the HAZ. This seems to be the case also if the conditions for the additional forging was varied, i.e., the time for start of forging, the duration of the additional forging, and the magnitude of the prescribed displacement. The difference between experiments and FE simulations may also be attributed to the non-controlled modification of the forging distance during welding. GTG reported a variation between 6 and $9 \mathrm{~mm}$ in the case of field welding conditions. This fact also motivates the variation in comparison with the longitudinal hardness profile along the weld.

The FE-simulated width of the HAZ can also be compared with experimental results from the literature, Chen et al. [2], where conventional ATW was carried out using different preheating times. Table 3 shows this comparison, here described as the FZ and the HAZ. Note that here the same definition of HAZ was used, i.e., points that have experienced a temperature exceeding $723{ }^{\circ} \mathrm{C}$ are defined as being in the HAZ. The FE simulations reach magnitudes for the width that are in the upper limit of the experimental range, specifically at the web center and web-to-foot transition area. When considering a forging displacement of $12 \mathrm{~mm}$, the reduction of the $\mathrm{FZ}+\mathrm{HAZ}$ width in this case is approximately half, i.e., $6 \mathrm{~mm}$. Note, again, that the width
Fig. 19 Relationship between the metallurgical gradient and the hardness variation across a thermite weld

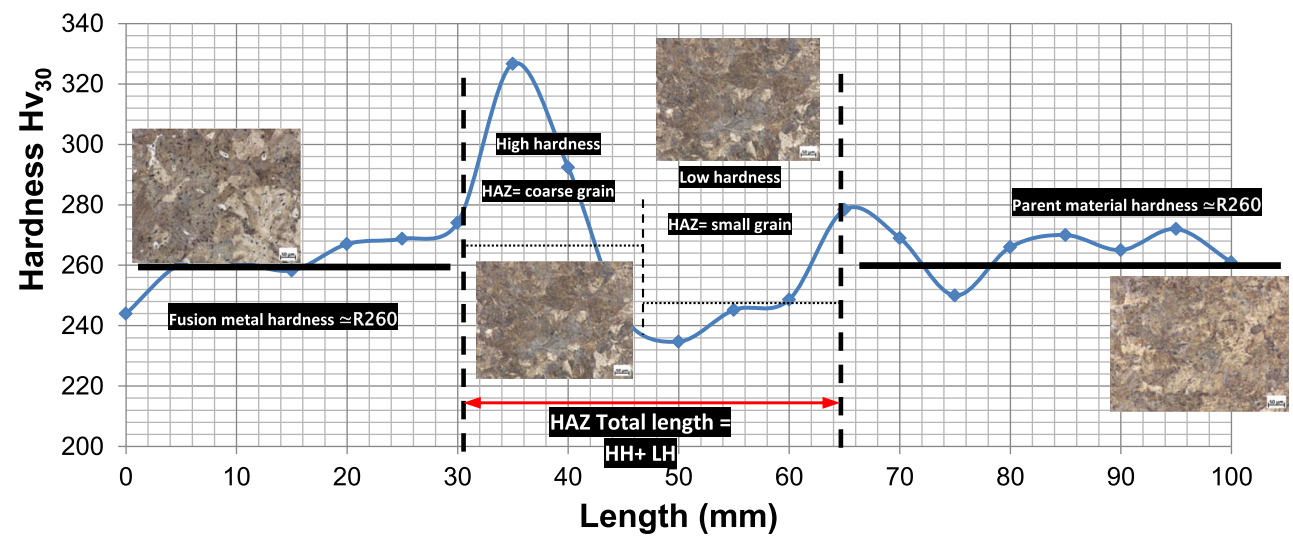




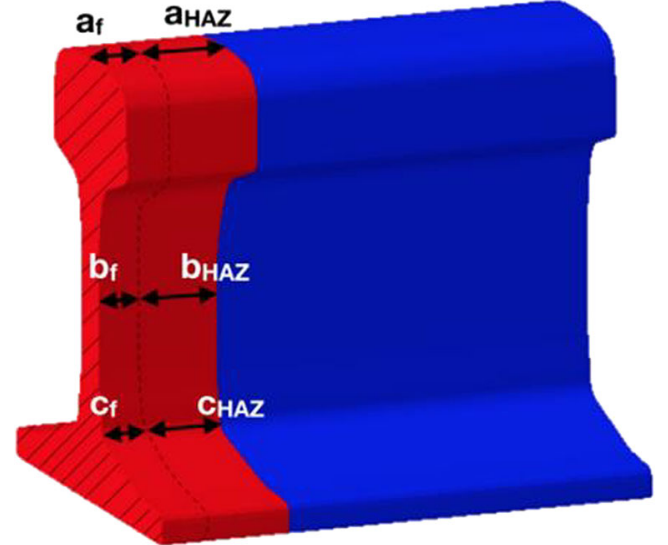

Fig. 20 Measures of the width of the FZ and HAZ used in the FE simulations and in Tables 2 and 3

of the HAZ is determined by the heat input and is not directly coupled to the additional forging; however, material that will become the HAZ may have been plastically deformed during the forging. The agreement with Chen et al. [2] is reasonably good, considering some differences in the thermite weld procedure used in Chen et al. [2] and in the WRIST project [19].

\section{Discussion}

As seen above, and in the literature, welding of rails using ATW or FBW will give a residual stress field with both vertical and longitudinal components having large tensile magnitudes in the web region in the HAZ of the rail close to the weld metal. This is a region where there may be less redistribution of stresses during operation, as compared with the rail head (due to rolling contact loads with large plastic deformations) and in the rail foot (due to bending loads). This detrimental effect of welding residual stresses on the fatigue behavior of rail welds and methods to improve the fatigue of rail welds, mainly for FBW, have been studied in [7, 14-17] and in an overview by Josefson [27]. For other welding methods, Kabo et al. [28] studied repair welding of a rail and assessed the influence on rolling contact fatigue. Though only a section of the rail was studied by Kabo et al. [28], high tensile residual stresses were found at the rail head surface after the repair welding; these stresses are redistributed, even a shake-down effect, on the rail head surface, so the influence on subsequent rolling contact fatigue cracks is higher, but moderate, in a layer below the rail head upper surface.

The shape of the residual stress field for the ATW was seen to be relatively unaffected by the application of an additional forging very early after pouring of molten weld metal. This may be expected as the build-up of residual stresses mainly takes place at lower temperatures, i.e., later in the cooling stage after pouring, see Figs. 10 and 11.

It is interesting to find that the additional forging (and corresponding compression of the rail at the weld zone) does not give a markedly reduced width of the FZ + HAZ, either in the simulations or from the metallurgic examinations. Use of an additional forging (the ALFONS module) shortly after pouring will give a strong plastic compression of the warm FZ. This will be seen after cooling to room temperature as high values for the transverse (tensile) and longitudinal (compressive) plastic strain components, although the cooling phase and the phase transformation from austenite (present at forging) to pearlite introduces large strain thermal strain changes, giving additional plastic strains. The solid state phase transformation is modeled with a volume increase (through a change in thermal strain, see Fig. 4d), and also a resetting of the hardening parameter (accumulated effective plastic strain) so that hardening achieved in the austenite phase will not affect hardening in the pearlite phase. The HAZ, which also have been plastically deformed during the forging, will be marginally affected by the forging. The resulting effect is that only a part of the imposed displacement at forging is seen in the final width of the FZ and HAZ.

\section{Conclusions}

A full 3D model of the ATW process has been developed. It includes all stages of the ATW process specifically, preheating, tapping, pouring, shearing, and cooling. During the cooling phase, the additional forging pressure is applied, i.e., the ALFONS module, and later, excess material is sheared off. With this FE model, the effect of varying several process
Table 2 Comparison of FZ and HAZ widths using conventional ATW or ATW with additional forging

\begin{tabular}{lllllll}
\hline Welding method/distance* $(\mathrm{mm})$ & $\mathrm{a}_{\mathrm{f}}$ & $\mathrm{a}_{\mathrm{HAZ}}$ & $\mathrm{b}_{\mathrm{f}}$ & $\mathrm{b}_{\mathrm{HAZ}}$ & $\mathrm{c}_{\mathrm{f}}$ & $\mathrm{c}_{\mathrm{HAZ}}$ \\
\hline Conventional ATW FE simulations & 12.1 & 41.7 & 12.1 & 36.9 & 12.2 & 36.8 \\
$\begin{array}{l}\text { ATW with ALFONS, } 12 \text { mm }(2 \times 6) \text { FE simulations } \\
\text { Conventional ATW experimental evaluation }\end{array}$ & 11.7 & 38.4 & 11.4 & 34.7 & 11.1 & 35.0 \\
$\quad$ (based on hardness profile) & & 36 & & 28 & & 30 \\
$\begin{array}{l}\text { ATW with ALFONS experimental evaluation } \\
\quad \text { (based on hardness profile) }\end{array}$ & 35 & & 32 & & 30 \\
\hline
\end{tabular}

$*_{\mathrm{f}}, \mathrm{a}_{\mathrm{Haz}}, \mathrm{b}_{\mathrm{f}}, \mathrm{b}_{\mathrm{HAZ}}, \mathrm{c}_{\mathrm{f}}, \mathrm{c}_{\mathrm{HAZ}}$ are shown in Fig. 20 
Table 3 Comparison of FZ + $\mathrm{HAZ}$ widths to experiments performed by Chen et al. [2]

\begin{tabular}{llll}
\hline Welding method/distance* $(\mathrm{mm})$ & $2 \times\left(\mathrm{a}_{\mathrm{f}}+\mathrm{a}_{\mathrm{HAZ}}\right)$ & $2 \times\left(\mathrm{b}_{\mathrm{f}}+\mathrm{b}_{\mathrm{HAZ}}\right)$ & $2 \times\left(\mathrm{c}_{\mathrm{f}}+\mathrm{c}_{\mathrm{HAZ}}\right)$ \\
\hline Experiments Chen et al. [2]. & $98-120$ & $81-96$ & $81-92$ \\
Conventional ATW & 107.6 & 97.9 & 97.8 \\
ATW with ALFONS, 12 mm (12))mm) & 100.2 & 92.2 & 92.2 \\
\hline
\end{tabular}

$*_{\mathrm{f}}, \mathrm{a}_{\mathrm{Haz}}, \mathrm{b}_{\mathrm{f}}, \mathrm{b}_{\mathrm{HAZ}}, \mathrm{c}_{\mathrm{f}}, \mathrm{c}_{\mathrm{HAZ}}$ are shown in Fig. 20 parameters on the final HAZ width and residual stress can be studied.

The FE model has been calibrated thermally with experimental results for a conventional ATW where temperatures have been measured at several points on the rail during the preheating and cooling stages.

The thermal analyses and a metallographic examination show that a fully pearlitic structure is found after the ATW process, and that applying an additional forging, i.e., the ALFONS module, will result in a marginally reduced width of the FZ and HAZ in the rail. The FE simulations indicate, however, that the additional forging pressure, may lead to higher plastic strains at elevated temperatures which in turn may increase the risk for hot cracking.

ATW will result in a residual stress field with high tensile residual vertical stresses in the web of the rail. The longitudinal residual stress is also highly tensile in this region. This is in good agreement with experimental results from the literature. Applying an extra forging stage, i.e., the ALFONS module, will result in small changes in the residual stress field compared with the conventional ATW. Hence, the use of ALFONS has no significantly negative effect on the residual stress state in the welded structure.

Acknowledgments Open access funding provided by Chalmers University of Technology. The present work has been undertaken within the European Project WRIST, Innovative Welding Processes for New Rail Infrastructures (Grant agreement 636164), part of the Horizon 2020 program.

Funding information Two authors acknowledge part support from CHARMEC - Chalmers Railway Mechanics.

Open Access This article is licensed under a Creative Commons Attribution 4.0 International License, which permits use, sharing, adaptation, distribution and reproduction in any medium or format, as long as you give appropriate credit to the original author(s) and the source, provide a link to the Creative Commons licence, and indicate if changes were made. The images or other third party material in this article are included in the article's Creative Commons licence, unless indicated otherwise in a credit line to the material. If material is not included in the article's Creative Commons licence and your intended use is not permitted by statutory regulation or exceeds the permitted use, you will need to obtain permission directly from the copyright holder. To view a copy of this licence, visit http://creativecommons.org/licenses/by/4.0/.

\section{References}

1. Meric C, Atik E, Sahlin S (2002) Mechanical and metallurgical properties of welding zone in rail welded via thermite process. Sci Technol Weld Join 7:172-176

2. Chen Y, Lawrence FV, Barkan CPL, Dantzig JA (2006) Heat transfer modelling of rail thermite welding. Proc ImechE Part F: J Rail Rapid Transit 220:207-2017

3. Mutton PJ, Alvarez EF (2004) Failure modes in aluminothermic rail welds under high axle load conditions. Eng Fail Anal 11:151-166

4. Chen Y, Lawrence FV, Barkan CPL, Dantzig JA (2006) Weld defect formation in rail thermite welds. Proc IMechE, Part F: J Rail Rapid Transit 220:373-384

5. Yu X, Feng L, Qin A, Zhang Y, He Y (2015) Fracture analysis of U71Mn rail flash-butt welding joint. Case Stud Eng Fail Anal 4:20-25

6. Godefroid LB, Faria GL, Candido LC, Viana TG (2015) Failure analysis of recurrent cases of fatigue fracture in flash butt welded rails. Eng Fail Anal 58:407-416

7. Webster PJ, Mills G, Kang WP, Holden TM (1997) Residual stresses in alumino-thermic welded rails. J Strain Anal Eng Des 32:389400

8. Jezzini-Aouad M, Flahaut P, Hariri S, Zakrewski D, Winiar L (2010) Improving fatigue performance of alumino-thermic rail welds. Appl Mech Mater 24-25:305-310

9. Mutton PJ, Soeleiman S (1989) Performance of aluminothermic welds under high axle loads. Proceedings of the fourth heavy haul railway conference, Brisbane, Australia

10. Skyttebol A, Josefson BL (2005) Numerical simulation of flash butt welding of railway rails. In: Cerjak $\mathrm{H}$, Bhadeshia $\mathrm{HKDH}$, Kozeschnik E (eds) Mathematical modelling of weld phenomena 7. Verlag der Technischen Universität Graz, Graz, pp 943-964

11. Tawfik D, Mutton PJ, Kirstein O, Chiu WK (2007) A comparative study between FEA, trepanning and neutron strain diffraction on residual stresses in flash-butt welded rails. J Neutron Res 15:199-205

12. Ma N, Cai Z, Huang H, Deng D, Murakawa H, Pan J (2015) Investigation of welding residual stress in flash-butt joint of U71Mn rail steel by numerical simulation and experiment. Mater Des 88:1296-1309

13. Ghazanfari M, Tehrani PH (2019) Experimental and numerical investigation of the characteristics of flash-butt joints used in continuously welded rails. Proc IMechE, Part F: J Rail Rapid Transit 234: 65-79. https://doi.org/10.1177/0954409719830189

14. Skyttebol A, Josefson BL, Ringsberg JW (2005) Fatigue crack growth in a welded rail under the influence of residual stresses. Eng Fract Mech 72:271-285

15. Josefson BL, Ringsberg JW (2009) Assessment of uncertainties in life prediction of fatigue crack initiation and propagation in welded rails. Int J Fatigue 31:1413-1421

16. Salehi I, Kapoor A, Mutton PJ (2011) Multi-axial fatigue analysis of aluminothermic welds under high axle load conditions. Int $\mathrm{J}$ Fatigue 33:1324-1336

17. Tawfik D, Mutton PJ, Chiu WK (2008) Experimental and numerical investigations: alleviating tensile residual stresses in flash butt 
welds by localized rapid post-weld heat treatment. J Mater Process Technol 196:279-291

18. Grossoni I, Shackleton P, Bezin Y, Jaiswal J (2017) Longitudinal rail weld geometry control and assessment criteria. Eng Fail Anal $80: 352-367$

19. WRIST - Innovative Welding Processes for New Rail Infrastructures (2015) The European Union, horizon 2020 program, Grant agreement 636164. http://www.wrist-euproject.eu

20. Banton I (2016) Private communication. Thermite Weld 2016. http://thermit-welding.com

21. Bevan A., Jaiswal J., Smith A., Cabral MO. (2018) Judicious selection of available rail steels to reduce life cycle costs, Institute of Railway Research, University of Huddersfield, Huddersfield Queensgate and Institute of Transport Studies (ITS), University of Leeds, Leeds, Technical Report

22. Tuchkova N (2011) Prozessanalyse und simulationstechnische Optimierung des aluminothermishen Schweißes von Schienen (in German). Dissertation, Otto-von-Geuricke-Universitat, Magdeburg, Germany

23. Ahlström J (2016) Residual stresses generated by repeated local heating events - modelling of possible mechanisms for crack initiation. Wear 366-367:180-187
24. Lindgren L-E (2001) Finite element modeling and simulation of welding, part 2: improved material modeling. J Therm Stresses 24:195-231

25. Jonsson M, Karlsson L, Lindgren L-E (1983) Thermal stresses, plate motion and hot cracking in butt-welding. In: Carlsson J, Ohlsson NG (eds) Mechanical behaviour of materials - IV, Proceeding of the Fourth International Conference. Pergamon Press, Oxford, pp 273-279

26. Yang Y, Dong P, Zhang J, Tian X (2000) A hot-cracking mitigating technique for welding high strength aluminum alloy. Weld J 79:8s-17s

27. Josefson BL (2014) Welding of rails and effects of crack initiation and propagation. In: Hetnarski R (ed) Encyclopedia of thermal stresses. Springer, Dordrecht, pp 6589-6594

28. Kabo E, Ekberg A, Maglio M (2019) Rolling contact fatigue assessment of repair rail welds. Wear 436-437:203030

Publisher's note Springer Nature remains neutral with regard to jurisdictional claims in published maps and institutional affiliations. 